\title{
BMJ Open Experiences of older people dying in nursing homes: a narrative systematic review of qualitative studies
}

\author{
Nan Greenwood, Emma Menzies-Gow, David Nilsson, Dawn Aubrey, \\ Claire L Emery, Angela Richardson
}

To cite: Greenwood N, Menzies-Gow E, Nilsson D, et al. Experiences of older people dying in nursing homes: a narrative systematic review of qualitative studies. BMJ Open 2018;8:e21285. doi:10.1136/ bmjopen-2017-021285

- Prepublication history for this paper is available online. To view these files, please visit the journal online ( http://dx.doi. org/10.1136/bmjopen-2017021285).

Received 31 December 2017 Revised 27 April 2018 Accepted 4 May 2018
Check for updates

Faculty of Health, Social Care and Education, Kingston University and St George's University of London, London, UK

Correspondence to Dr Nan Greenwood; Nan.Greenwood@sgul.kingston. ac.uk

\section{ABSTRACT}

Objectives To identify and synthesise qualitative research from 2001 investigating older people's (65+ years) experiences of dying in nursing and care homes.

Methods and outcomes Eight electronic databases (AMED, ASSIA, CINAHL Plus, Embase, HMIC, Medline, PsychINF0 and Scopus) from 2001 to July 2017 were searched. Studies were included if they were qualitative, primary research and described the experiences of dying in nursing or care homes from the perspectives of the older people themselves, their families or staff. Study quality assessment was undertaken to systematically assess methodological quality, but no studies were excluded as a result.

Results 1305 articles were identified. Nine met the inclusion criteria. North American studies dominated. Most used a mixture of observations and interviews. All the included studies highlighted the physical discomfort of dying, with many older people experiencing potentially avoidable symptoms if care were to be improved.

Negative psychosocial experiences such as loneliness and depression were also often described in addition to limited support with spiritual needs.

Conclusions More qualitative research giving a holistic understanding of older people's experiences of dying in residential care homes is needed. Undertaking research on this topic is challenging and requires great sensitivity, but the dearth of qualitative research from the perspectives of those most closely involved in older people's deaths hampers service improvement.

\section{INTRODUCTION}

Worldwide, life expectancy is continuing to rise, and increasing numbers of older people require support towards the end of their lives with significant proportions of older people living in care or nursing homes. For example, across Europe and North America, more than two-thirds of care home residents are aged 80 years or older. ${ }^{1}$ In parallel with this, the proportion of older residents dying in care homes is rising across the world. ${ }^{2}$ In England and Wales, for example, in 2006, $19.2 \%$ of older people aged 65 years and over died in care homes, ${ }^{3}$ compared with $24.7 \%$ a decade later. ${ }^{4}$ Therefore, the importance

\section{Strengths and limitations of the study}

- The qualitative focus of this review broadens our understanding of older people's experiences by highlighting important psychosocial aspects of the experience frequently omitted in quantitative studies.

- Despite being comprehensive, this review only identified nine studies, thereby highlighting an important gap in the literature.

- Study authors used varying criteria to identify the end of life or dying in older people which presented challenges to synthesising study findings.

- The most recent study was published in 2011, and all research came from Western countries.

of providing good end-of-life care for older people in nursing and care homes is growing.

The Gold Standards Framework was first introduced in 2000 in the UK to standardise the provision of consistent, coordinated care for people nearing the end of life. It has since been remodelled to train care home staff to deliver standardised palliative care for all patients approaching the end of life. ${ }^{5}$ More recently, the End of Life Care Strategy ${ }^{6}$ introduced new care pathways and initiatives to improve end-of-life care, such as Preferred Priorities of Care, a tool to enable healthcare staff to work with patients to document their wishes as they approach the end of life. In view of the variable quality of end-of-life care, national concern with the topic has continued with the development in the UK of the National End of Life Care Partnership. ${ }^{7}$ These programmes have been recognised and adopted in many other countries. Programmes such as the Liverpool Care Pathway, for example, have been disseminated to over 20 countries in a range of settings including care homes. ${ }^{8}$

Evidence relating to the implementation of end-of-life care policy in care homes is sparse and limited. For example, a review 
of the literature relating to the efficacy of palliative care interventions for older people living in care homes ${ }^{9}$ found only three relevant studies. All were undertaken in the USA, and all were described as 'poor' quality. The authors suggested that care home structure and culture may be an important barrier or facilitator of the success of any approach to palliative care influencing the generalisability of the interventions. They also highlighted that the outcome measures used within the studies were predominantly process related, which may not automatically translate to positive patient experiences and that future studies should incorporate residents' views of their care. ${ }^{9}$ A UK-based evidence synthesis ${ }^{10}$ of the implementation of the end-of-life care policy in care homes also only identified three relevant studies. Some improvement in resident outcomes and in the ability of staff to recognise and deliver care to meet resident needs were highlighted. However, the dearth of studies and the possibility of other factors influencing care mean it is not possible to be confident that these improvements could be attributed to these interventions. Here, too, the evidence failed to highlight the experiences of those receiving the care.

Advance care planning, involving advance discussions of care needs and preferences at the end of life has been studied quite extensively in a variety of settings. ${ }^{11} \mathrm{~A}$ systematic review of randomised controlled trials found that advance care planning for older adults facilitated increased documentation of care preferences, advance directives and improved family outcomes, but none of the studies measured patient outcomes relating to quality of life and symptom management. ${ }^{11}$ The majority of studies in another review ${ }^{12}$ investigated 'do not resuscitate orders' and advance care directives with only a few focusing on patient and family experiences. A case study of four care homes in the UK also revealed that advance care planning is frequently seen as a 'tick-box' exercise while it should be an individualised process, discussed at the right time and handled sensitively. However, this requires a positive culture in care homes with good leadership and staff training if it is to be effective. ${ }^{13}$ Taken together, these publications highlight the need to bring together the evidence for how end of life is experienced by those at the centre of it-the older people themselves. Without this essential perspective, it might be argued that their care is unlikely to improve.

Future preferences concerning end-of-life care in care homes have also been investigated. For example, in one interview study, many older people in care homes said they were ready to die but were concerned about the process of dying and wanted a peaceful, pain-free death, without life-saving treatment or hospital intervention. ${ }^{14}$ Similarly, some acceptance that end of life was approaching was also reported, but there were differences of opinion regarding the readiness to engage in end-of-life care conversations. ${ }^{14}$ Many had not discussed this with nursing home staff. In a similar vein, missed opportunities to have conversations about end of life with residents and assumptions about end of life preferences were also reported elsewhere among nursing home residents in the USA. ${ }^{15}$

A recent systematic review ${ }^{16}$ summarised the literature on what families and patients believe could be done to improve end-of-life care in nursing homes. The importance of health professionals anticipating care and support needs and providing guidance were emphasised with many participants wanting greater availability of doctors. Patients' preferences were not always recognised and participants saw room for improvement.

There is a considerable body of quantitative literature, often retrospective perceptions a long time after death, that focuses on the process of dying in care homes, with emphasis on symptom occurrence such as pain and dyspnoea or the frequency of clinical events. ${ }^{17} 18$ Such quantitative research tends to break the experience down into measurable outcomes while not capturing the experience holistically. Although the quantitative literature is important and highlights many of the negative aspects of dying such as pain, it inevitably relies on methods such as structured questionnaires and cannot therefore be reported in the participants' own words. Consequently, quantitative methods alone may fail to capture fully less tangible psychosocial aspects of dying, such as its spiritual, psychological and emotional facets.

\section{Review aims}

As no review synthesising the qualitative research evidence relating to the experiences of older people of dying in care homes was found, this review therefore aimed to identify and synthesise the findings of qualitative studies investigating older people's (aged 65 years or over) experiences of dying in nursing or care homes. The ethical and practical challenges of undertaking research with people very close to death mean that there was likely to be limited research with older people themselves as participants. We therefore also sought to identify and synthesise research that described the experiences of these older people as perceived by their families and staff working closely with them.

\section{Definitions}

For the purposes of this review, experience encapsulates the following: psychological and emotional aspects of dying such as distress, anxiety, depression, autonomy and physical aspects such as pain or dyspnoea, sleep, cleanliness and finally, spiritual dimensions, such as faith, meaning and purpose.

Defining dying is very challenging with the term in the literature being used in a range of ways. The focus of this review was on older people at the end or very near the end of life. For this review, this was taken as 'dying'. Each identified paper was scrutinised with this in mind. We were led by how the authors described or defined dying but only included papers where the review team agreed that the majority of participants were close to death. 


\section{METHODS}

The review followed the Centre for Reviews and Dissemination guidelines (CRD 2009) ${ }^{19}$ and was reported using the Preferred Reporting Items for Systematic Reviews and Meta-analysis (PRISMA). ${ }^{20}$ It was registered on PROSPERO (CRD42017055954). ${ }^{21}$

\section{Inclusion criteria}

The following publication types were included: primary research studies investigating older people's (aged over 65 years) experiences of dying in residential care (eg, nursing or care homes, retirement homes and assisted living facilities) whether from the perspective of the older person, nursing home staff or informal carers; qualitative studies; mixed-methods studies where the qualitative findings could be separated from the quantitative findings; and published in peer-reviewed journals in the English language.

\section{Exclusion criteria}

The following were excluded: studies investigating the experiences of dying in other care contexts including hospital, hospices and older people's own homes; studies investigating the experiences of nursing home staff; studies investigating informal carers' own experiences; quantitative studies; case studies; non-peer reviewed journal articles; grey literature (eg, $\mathrm{PhD}$ theses and conference proceedings); and review and comment articles.

\section{Search strategy}

Eight electronic databases were searched from January 2001 to October 2015 and then updated in July 2017: Allied and Complementary Medicine Database (AMED), ASSIA, CINAHL Plus, Embase, HMIC, Medline, PsychINFO and Scopus. Searches were undertaken from 2000, because the National Service Framework for Older People, a seminal policy with wide-reaching significance, was published in 2001. This date would ensure that any relevant study was captured.

The searches combined the following terms: older people, dying, nursing or care homes and qualitative studies.

\author{
An example search strategy (MEDLINE) that was adapted for \\ the other databases \\ 1. exp “ Aged, 80 and over" / or Aging / or exp Aged / \\ or older people.mp. \\ 2. exp Frail Elderly/ \\ 3. aged.tw. \\ 4. elderly.tw. \\ 5. geriatric*.tw. \\ 6. older people*.tw. \\ 7. ag?ng.tw. \\ 8. or $/ 1-7$ \\ 9. exp Death / or exp Attitude to Death / or death.mp. \\ 10. end of life.tw. \\ 11. dying.tw. \\ 12. aged care facilities.tw. \\ 13. residential care.tw.
}

14. old* people* home.tw.

15. care home*.mp,tw.

16. nursing home*.mp,tw.

17. long term care.tw.

18. assisted living.tw.

19. or/ $9-11$

20. or/ $13-18$

21. 8 and 19 and 20

22. interview:.mp.

23. experience:.mp.

24. qualitative.tw.

25. 22 or 23 or 24

26. 21 and 25

27. limit 26 to (English language and humans and year="2001-Current")

\section{Additional sources}

To identify any relevant studies that may have not been identified through the electronic database searches, references in the only relevant review ${ }^{16}$ and the references lists of all the included articles were scrutinised. In addition, where contact details were available, we contacted the authors of the selected articles and asked if they could suggest any other relevant studies.

\section{Screening for relevance}

After duplicate removal, the titles and abstracts of studies identified in the electronic and hand searches were independently screened by a minimum of three members of the review team. Those studies identified as potentially relevant were then retrieved for full-text review and scrutinised by a minimum of four team members. Throughout the entire process, disagreements were resolved by discussion.

\section{Quality assessment and scoring}

Assessment of study quality in qualitative research is a contentious issue because of the differing paradigms and diversity in data collection, ${ }^{22}$ but it is also important to point out that the value of study quality ratings is limited by the fact that authors are often restricted in the details they can provide because of journal word counts. Therefore, quality assessment was undertaken to interrogate the methodological quality of the studies in a systematic fashion, rather than to exclude them. Quality assessment of the included studies was performed by a minimum of two reviewers using a qualitative quality scale. ${ }^{22}$ This scale was adapted from other scales ${ }^{23} 24$ and included consideration and rating of, for example, appropriateness of the study design and methods of analysis. An additional point was added to the original 11-point scale to identify whether researcher reflexivity ${ }^{23}$ was considered. Reviewers' ratings were generally in agreement, and consensus was reached with discussion over the few differences.

\section{Data extraction and synthesis}

Synthesis of the findings was narrative, but emphasis was given to identifying where studies gave insight into older people's experiences of dying in care or nursing homes 
using the following elements of experience: psychological, spiritual and cultural factors, care given and care received, physical symptoms and the physical environment. Data sources were wide and included interview and observational data. This diversity made synthesis more difficult. In order to capture what the study authors regarded as their most important findings, data incorporated in the themes and study conclusions came from their findings and discussion sections respectively. The synthesis was undertaken by three or more members of the review team and was intended to summarise and explain the study findings as presented in the text by the study authors.

\section{Patient and public involvement}

There was no patient and public involvement in this systematic review.

\section{RESULTS}

After duplicate removal, 1239 studies were identified from both the electronic and additional searches. No further studies were identified after reference list searching or contacting the included study authors. After abstract screening, 48 studies were identified for full-text review (figure 1).

Studies were excluded at this stage for a variety of reasons including inappropriate study foci, populations or settings and quantitative as opposed to qualitative methodology.

Nine studies fitted the inclusion criteria (table 1). Close scrutiny of three of these studies ${ }^{25-27}$ suggested to the team that they incorporated the same participants. We considered reporting them together in the review but kept them separate because they focused on different aspects of older people's experiences.

Two studies ${ }^{28} 29$ came close to inclusion but were finally excluded because, for example, their focus was more on service development or the participants were anticipating death rather than describing experiences of dying.

The earliest included study was published 16 years ago, ${ }^{30}$ and the most recent was seven years ago. ${ }^{31}{ }^{32} \mathrm{Six}$ studies were from North America, ${ }^{25-27} 303334$ two from
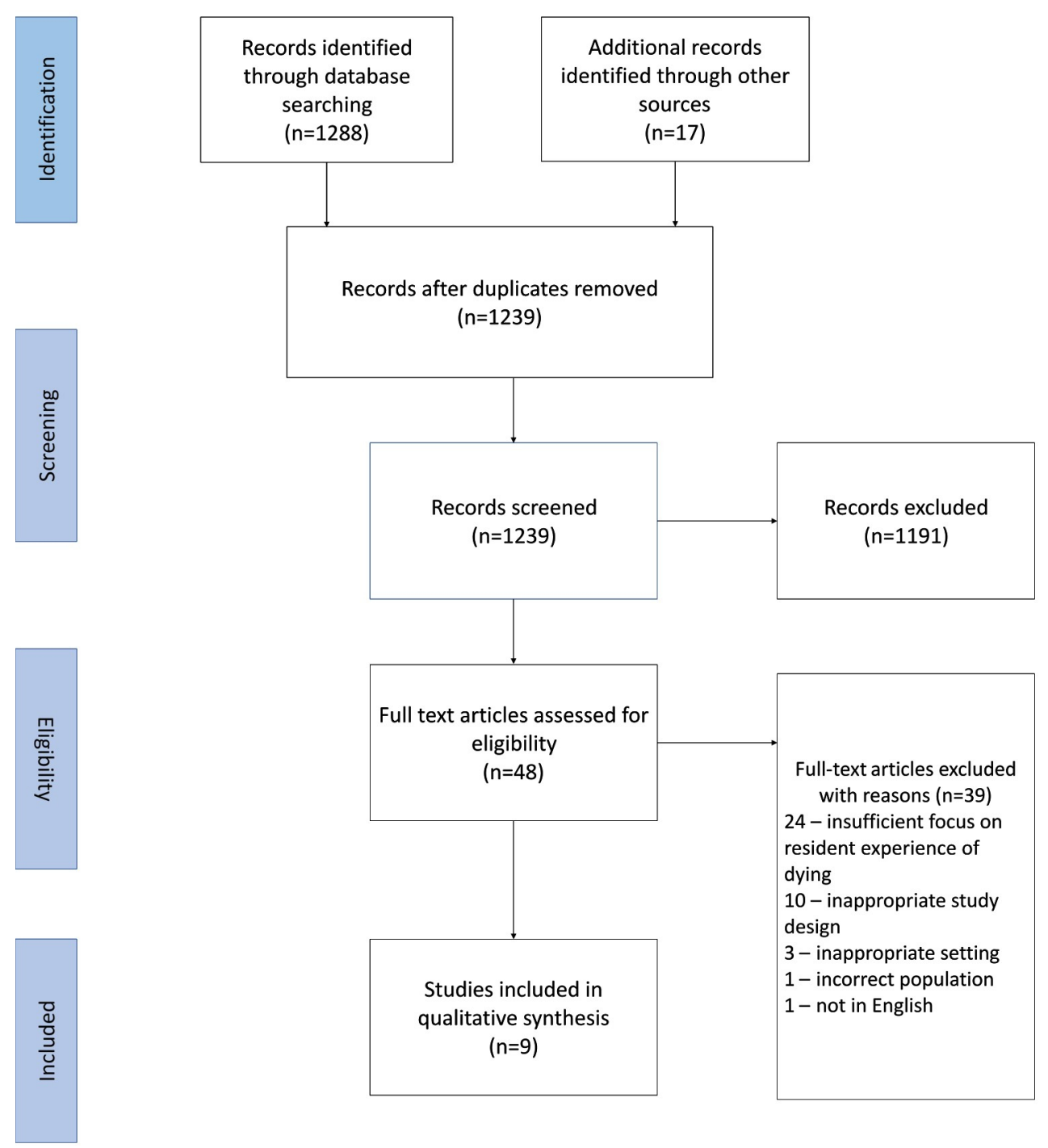

Figure 1 PRISMA flow diagram. ${ }^{20}$ PRISMA, Preferred Reporting Items for Systematic Reviews and Meta-analysis. 


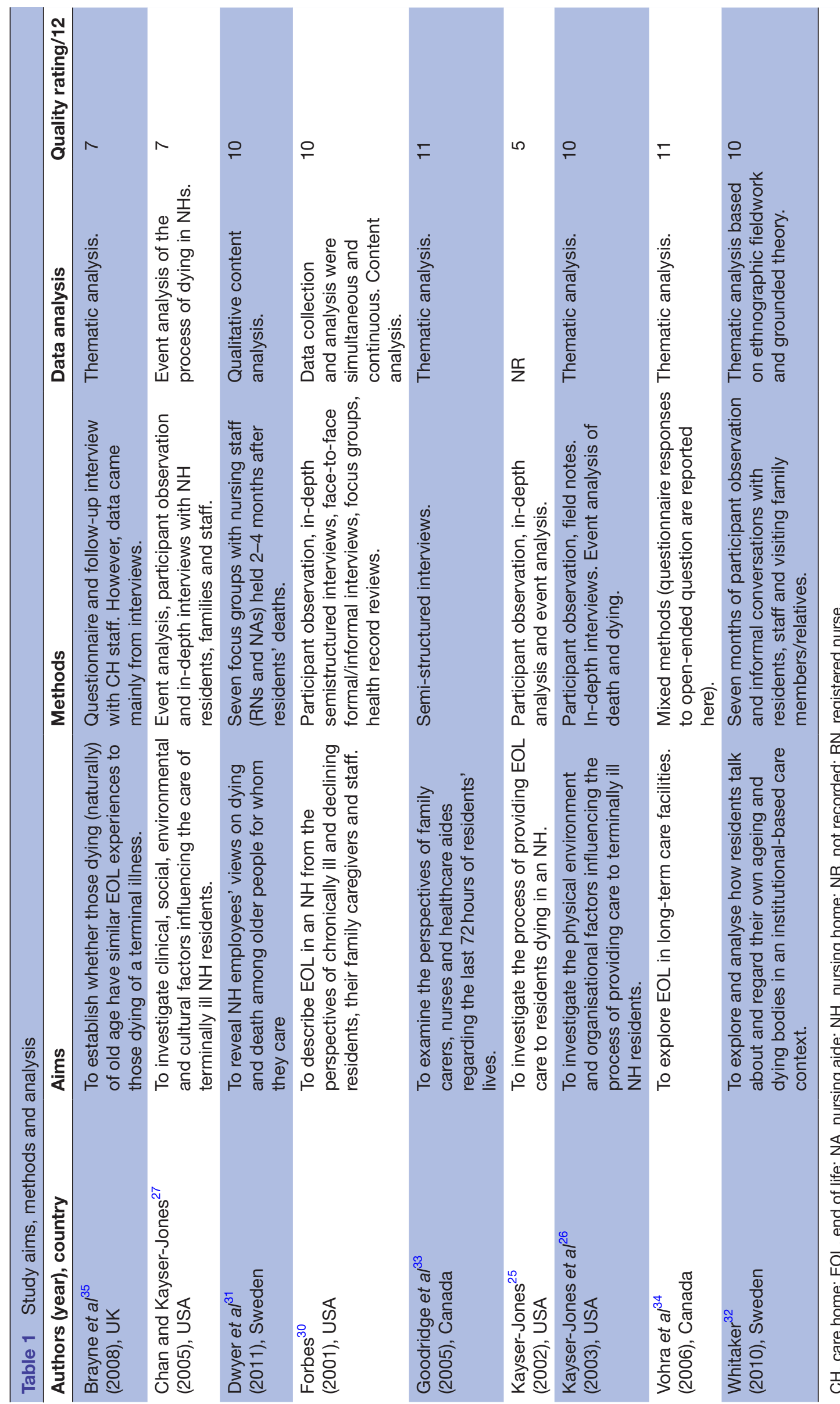


Sweden ${ }^{31} 32$ and one from the UK. ${ }^{35}$ Five studies investigated the perspectives of older people themselves, ${ }^{25-273032}$ five the perceptions of informal or family carers ${ }^{25} 26303234$ and four nursing home staff perceptions. ${ }^{25303135}$ Reporting of participant demographic details was often limited (table 2), but more information was generally provided about older people participants than the other groups. The older people were slightly more likely to be female than male, and the mean age of the majority was late $70 \mathrm{~s}$. Time to death was described in a variety of ways, but the vast majority of residents were close to death; authors described them as, for example, within hours or days of death at the time of the study or described how many died during the study. With the exception of one study, ${ }^{27}$ participants' ethnicity and religion were not reported. In terms of nursing home staff professional groups, nurses, nursing and healthcare assistants dominated, but participants also included doctors and social workers.

Except for one study that only undertook focus groups, ${ }^{30}$ most included studies incorporated either participant observation or interviews with participants. Interviews were mostly face-to-face, although Whitaker ${ }^{32}$ described data collection as incorporating 'informal conversations'. Written responses to an open-ended question on a questionnaire were included in one study. ${ }^{34}$ Data analysis approaches were related to data collection methods and included content analysis, thematic analysis and event analysis (table 2).

Overall, quality rating scores were good and ranged from 5 to 11 with a mean of 9.0. The primary quality issues that reduced ratings concerned poor reporting of methods, analysis and failure to report researcher reflexivity (table 1).

None of the studies reported having a theoretical background to their research, although they were mostly ethnographic in their approach.

Table 3 and table 4 show that all the included studies highlighted the physical discomfort of dying with many older people experiencing potentially avoidable symptoms such as pain, pressure sores, dyspnoea and thirst. In all studies except Whitaker $2010,{ }^{32}$ physical discomfort was highlighted in association with the care given to the older person, which was often seen as inadequate both by the researchers observing and the staff themselves. Aspects of care such as inappropriate food and drink, ${ }^{27}$ limited assessment ${ }^{25}$ and monitoring ${ }^{34}$ were also mentioned. Negative psychological aspects such as loneliness and depression were described in six studies. ${ }^{25} 30$ 32-35 Spiritual aspects of people's experiences such as religion and existential issues were also described. ${ }^{27} 3031$ 33-35 However, two studies highlighted that death ${ }^{30}$ and existential issues ${ }^{31}$ were seldom discussed unless raised by older people themselves. In contrast to the other studies, one $^{34}$ also highlighted good spiritual and psychological care received by the older people.

Chan and Kayser-Jones study ${ }^{27}$ stood out for focusing on the importance of cultural aspects of care emphasising the additional difficulties of Chinese people at the end of life in a USA care home in terms communication barriers and beliefs around illness and death. However, the uniqueness and individuality of older people's experiences were also clear in other studies (eg, refs 32 and 35).

The studies that included experience of dying from the perspective of the older people themselves are highlighted in table 4. Irrespective of the participant groups, many similarities are evident in the perceptions of this experience, particularly in relation to the centrality of physical symptoms and the care provided. Psychological and spiritual factors were also frequently reported themes.

\section{DISCUSSION}

Despite a comprehensive electronic database search and additional hand searching, we identified disappointingly few studies that described the subjective experiences of older people dying in nursing and care homes. One striking aspect of the searches was how few specifically investigated older residents' own experiences at the end of life. Perhaps unsurprisingly this was frequently investigated by proxy. However, those studies we did identify suggested these experiences were often poor.

Care must be taken in interpreting the findings given that few relevant studies were identified. However, seven of the nine included studies highlighted the physical discomfort of dying in a nursing or care home with older people often experiencing pain, pressure sores and thirst. Added to this, six studies described many people suffering psychologically; loneliness and depression were often highlighted. Although our aim was not originally to look at the relationship between care and experiences, most authors here made a clear direct link between inadequate care and these negative experiences, stating that they were often preventable or at least potentially alterable. This is significant as it demonstrates the impact of the physical environment and staff. Only one study ${ }^{27}$ specifically investigated cultural aspects of these older people's experiences, a significant omission given the importance of religion and culture surrounding death.

Whitaker ${ }^{32}$ highlighted how participants were reconciled to death and rather than fearing approaching death, accepted it, focusing more on their fear of a failing body. This was often dreaded more than dying. Although only one paper, it resonates with studies such as Mathie $e a^{14}$ that highlighted that despite acceptance of death, older people and staff were ambivalent about discussing end-oflife care. Such studies perhaps suggest that if care staff had open discussions about death and the potentially negative spiritual and psychological features of dying, the experiences of this vulnerable group might be better recognised, acknowledged and therefore improved. Maintaining dignity is important in all healthcare contexts but has perhaps not been sufficiently highlighted in relation to dying in residential care. Here it was only clearly highlighted in one study. ${ }^{25}$ This is perhaps surprising given its importance in healthcare generally. 


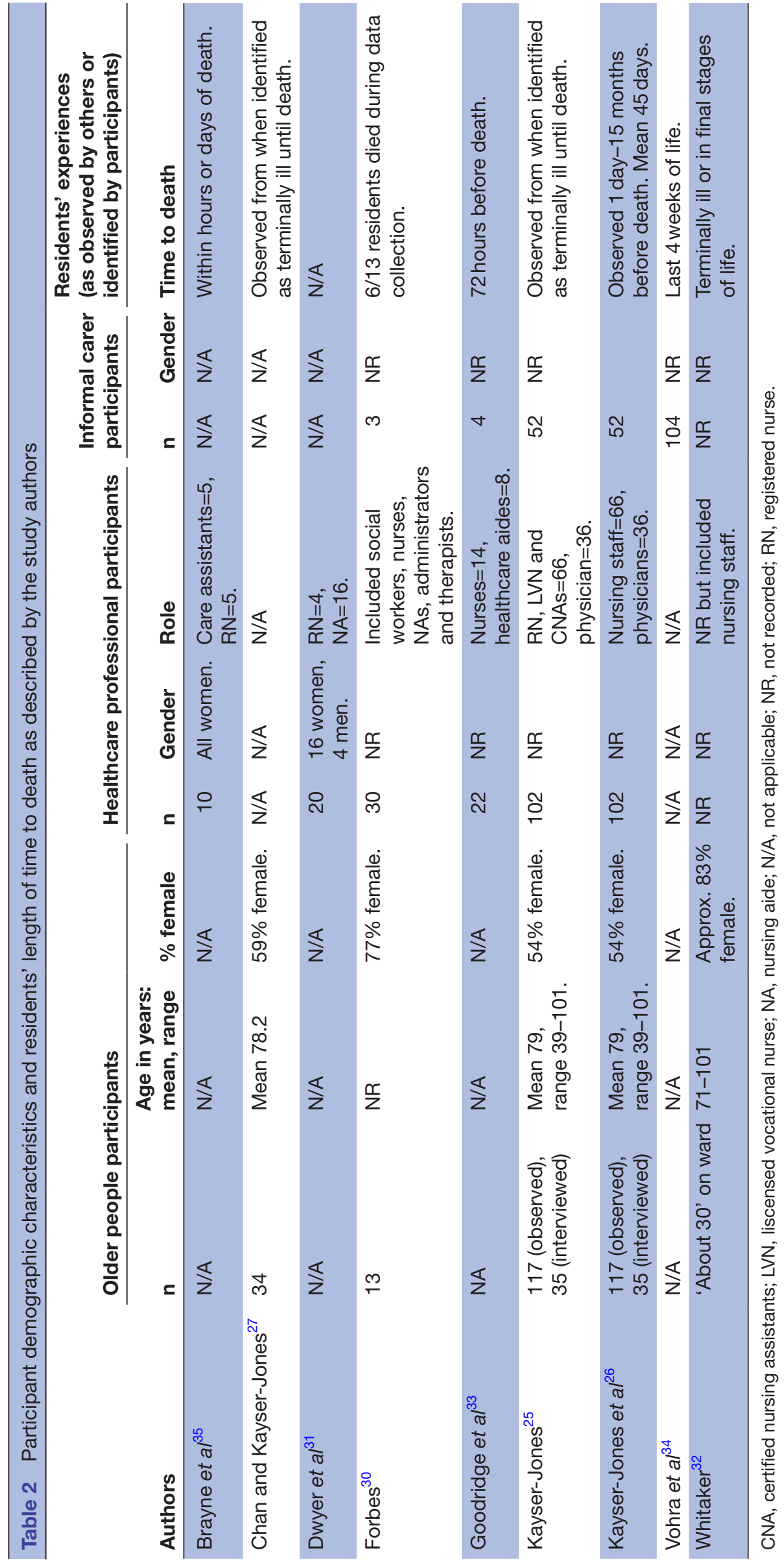




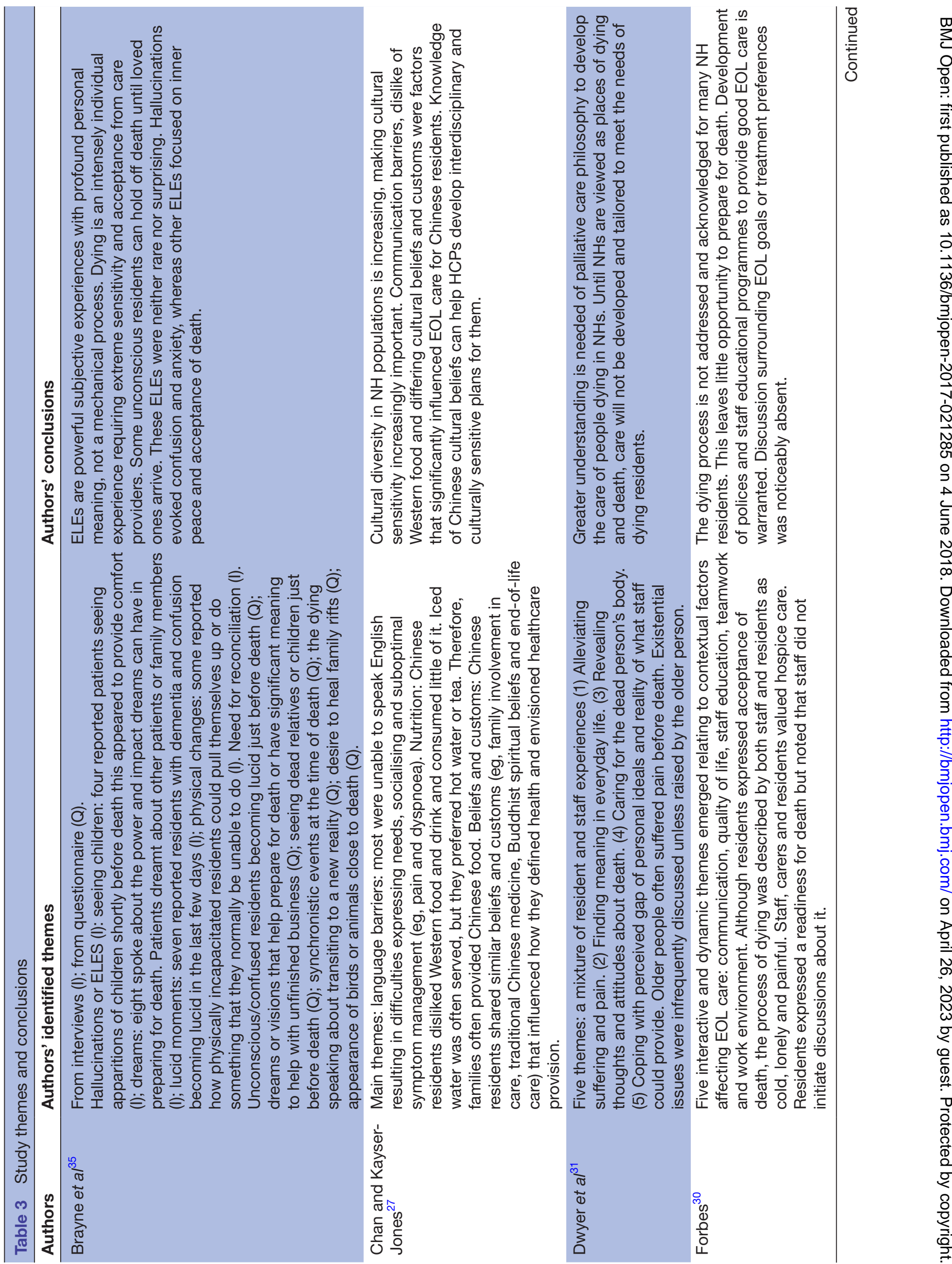




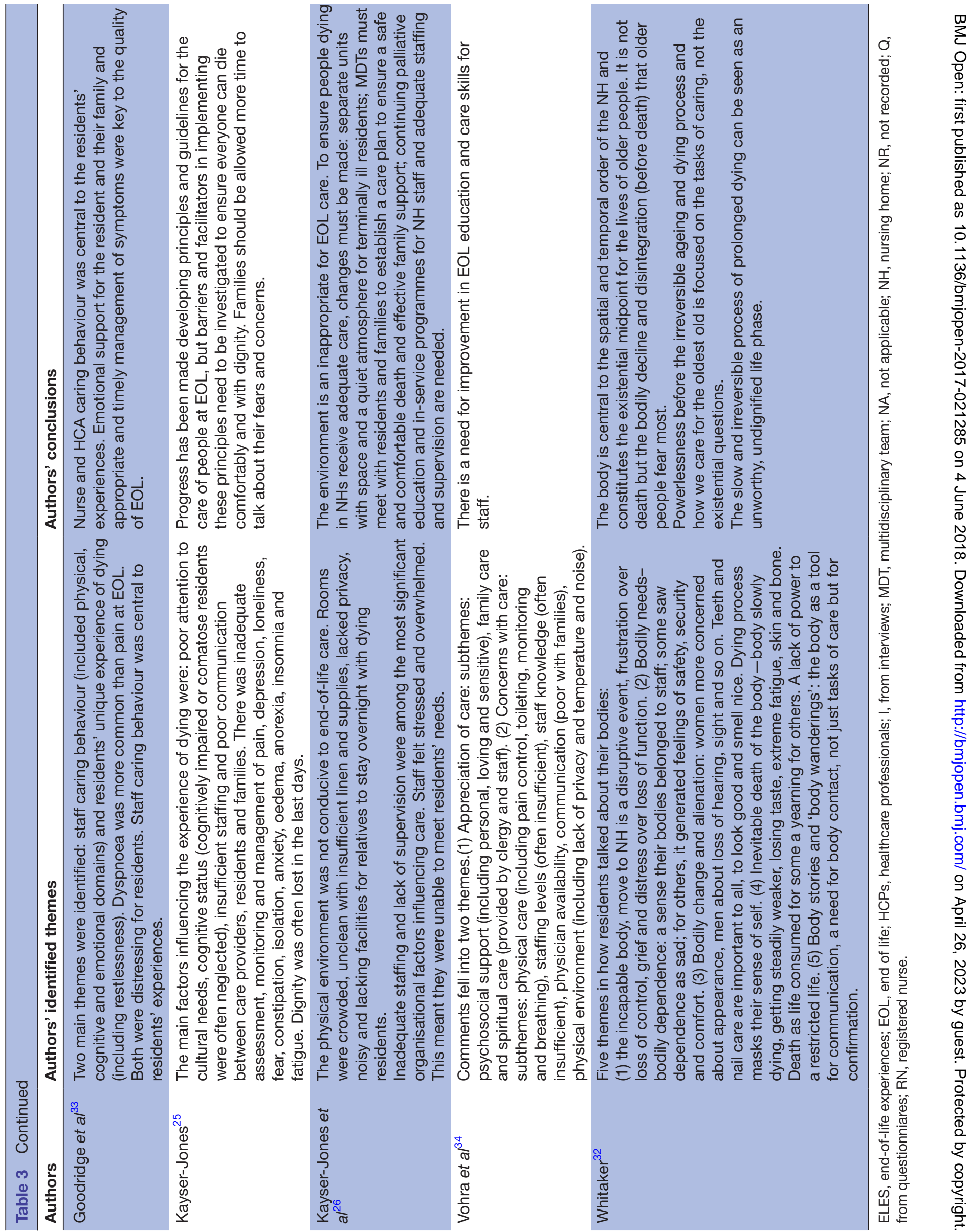


Table 4 Reported themes mapped onto the key aspects of older people's experiences as defined for the review.

\begin{tabular}{|c|c|c|c|c|c|c|}
\hline Authors & $\begin{array}{l}\text { Physical } \\
\text { symptoms }\end{array}$ & $\begin{array}{l}\text { Physical } \\
\text { environment }\end{array}$ & $\begin{array}{l}\text { Psychological } \\
\text { factors }\end{array}$ & $\begin{array}{l}\text { Cultural } \\
\text { factors }\end{array}$ & $\begin{array}{l}\text { Spiritual } \\
\text { factors }\end{array}$ & $\begin{array}{l}\text { Care given/ } \\
\text { received }\end{array}$ \\
\hline Brayne et $a l^{35}$ & $x$ & & $x$ & & $x$ & \\
\hline Chan and Kayser-Jones ${ }^{27}$ & $\mathbf{x}$ & $\mathbf{x}$ & & $\mathbf{x}$ & $\mathbf{x}$ & $\mathbf{x}$ \\
\hline Dwyer et $\left.a\right|^{31}$ & $x$ & & & & $x$ & $x$ \\
\hline Forbes $^{30}$ & $\mathbf{x}$ & $x$ & $\mathbf{x}$ & & $x$ & $\mathbf{x}$ \\
\hline Goodridge et $a^{33}$ & $x$ & & $x$ & & & $x$ \\
\hline Kayser-Jones ${ }^{25}$ & $\mathbf{x}$ & & $\mathbf{x}$ & & & $\mathbf{x}$ \\
\hline Kayser-Jones et a $\left.\right|^{26}$ & $\mathbf{x}$ & $\mathbf{x}$ & & & & $\mathbf{x}$ \\
\hline Vohra et $\left.a\right|^{34}$ & $\mathrm{x}$ & $x$ & $x$ & & $x$ & $\mathrm{x}$ \\
\hline Whitaker ${ }^{32}$ & $\mathbf{x}$ & & $\mathbf{x}$ & & & \\
\hline
\end{tabular}

$\mathrm{X}$ in bold text reflect studies incorporating the views of older people themselves.

Although only nine studies were identified, these studies have implications for our understanding of the what it is like to die in a care home or nursing home. The aspects of their experiences that were described suggest that more could be done to improve their experiences whether in terms of pain or other symptom relief or the overall physical environment. Insufficient staffing ${ }^{2634}$ and poor communication ${ }^{252730}$ were highlighted, although there was recognition of the challenges for staff. The role of families was not always highlighted but improved communication $^{2534}$ and flexibility in their involvement was suggested. ${ }^{26}$

The dearth of research in the area and the fact that the most recent included paper was published in 2011 was striking. There are many possible explanations for the overall lack of research; for example, investigating the topic is potentially very challenging and distressing and requires great sensitivity. It is also associated with many potential ethical concerns with such a vulnerable group. However, the fact that no relevant studies were found after 2011 is harder to explain. In the UK, policy changes relating to end-of-life care in $2008^{6}$ increased attention on palliative care, but despite this, we identified very few studies relevant to our research question either in the UK or elsewhere or after this date. Our literature searches suggest that the recent focus may be more on the impact of advance care planning, staff knowledge about care of dying patients and quantitative studies measuring outcomes of symptom management (eg, refs 11 and 12). As we have shown, very little published research focuses on subjective experiences, an essential facet to our review.

Some of the challenges in undertaking research in this area were perhaps also reflected in the difficulties we encountered during the review. The first of these related to the problems defining 'dying'. Authors often used very different definitions ranging from the "within hours or days of death ${ }^{35}$ to terminally ill or in the final stages of life ${ }^{32}$ and described this in varying ways (table 2). We decided to make pragmatic decisions together as a review team and to restrict the included studies to where scrutiny of the articles suggested to us that all or the majority of older people being observed or interviewed were very near to death, but this was clearly a limitation. Our decision to include only studies focusing on this period was to ensure we came as close as possible to capturing this final point in residents' lives, but we were reliant on our interpretation of the authors' descriptions.

Another difficulty during the review was defining what was meant by 'experiences' in this context. The quantitative literature gives some insight into the characteristics of dying in nursing homes, but the aim of the review was to try and capture the experience more holistically (rather than, for example, process outcomes). Therefore, quantitative studies were excluded.

Another challenge related to our aim to capture older people's experience in their own words. There are obvious potential ethical and practical issues in recruiting older people who are close to death, and many residents in nursing homes have cognitive and communication problems adding to the difficulties of gathering their experiences directly from them. Our initial searches identified several studies describing participants' future preferences surrounding their death (eg, ref 14) but few describing their experiences of dying. We also found many studies that investigated the often difficult experiences of those supporting the dying person such as healthcare staff $^{36}$ and family carers. ${ }^{37}$ The decision to include the perceptions of others, such as families and staff and not just the older people themselves, was taken to allow us to gain as much information as possible from those close to the older person but with the caveat that these had to be about their perceptions of the older persons' experiences. Unfortunately, we identified too few studies to allow us to compare the perspectives of these diverse groups and future research that simultaneously captures the experiences of the older person and those supporting them is needed to address this limitation.

\section{Strengths and limitations of the review}

Many of the review's limitations such as the paucity of recent relevant publications, and the diversity of authors' definitions of dying, have been highlighted 
earlier. In addition, the studies, although all qualitative, used different methods and had varying aims making synthesis challenging. It might be argued that the study that included analysis of open-ended questions in a questionnaire ${ }^{35}$ should not have been included, but the framing of the analysis was qualitative and it was included for comprehensiveness. However, overall the review was comprehensive including seven data bases, additional hand searching and input from authors of the selected papers. An additional strength of the review was the multidisciplinary nature of the review team that included researchers from nursing, social care and social sciences. This ensured a diversity of perspectives.

Another potential limitation was the exclusion of quantitative studies from the review. However, these studies were excluded because of their focus on clinical interventions, care processes and measurable outcomes such as pressure sores and dyspnoea, rather than the entire experience from participants' perspectives and in their own words. Participants' responses in quantitative research are constrained by the limited response options available and give only partial insight into specific aspects of experiences rather than capturing their experiences as a whole.

However, this decision to exclude quantitative studies potentially means that some aspects of people's experiences when dying, such as the extent of the pain and discomfort, may not be receiving sufficient emphasis here. Our study also highlighted the sometimes poor attention given to spiritual and psychological experiences, and authors often made an explicit link between inadequate care and negative experiences. However, the fact that many measurable clinical outcomes such as pain were described in the included qualitative studies suggests that findings from qualitative studies are complementary to those from quantitative ones. Case studies were also excluded because of their acknowledged general weaknesses in data analysis, reporting and overall lack of generalisability. ${ }^{38}$

We also did not include reports of older people who died in hospital after being moved from their nursing homes shortly before their death. This is a very important aspect of many people's experiences and is often regarded as undesirable. ${ }^{39}$ These transitions deserve recognition and exploration but have a different focus and were not included here.

Finally, we are also unable to say whether our findings are unique to nursing and care home contexts or whether these are a better or worse place to die than, for example, in hospital or at home.

\section{Strengths and limitations of the included studies}

An aim of our review was to provide a more holistic picture of the experiences of older people dying in care homes. By bringing these study findings together, we have arguably taken a small step in this direction, but future research needs to have this as a priority. Without an in-depth understanding of these experiences, it is hard to see how interventions can be expected to improve older people's experiences. Similarly, although potentially challenging, research needs to start including more people with cognitive difficulties to learn about their experiences. This will require greater user involvement in setting research questions and in subsequent research design but as their involvement is gaining momentum in other research, studies here could also benefit from this.

The included studies were of variable quality, and despite a rigorous search strategy, the latest study was published in 2010, making it difficult to be confident that the experiences highlighted here reflect the current situation. Certainly, in the UK, poor care in general is often highlighted, and campaigns such as the 'Fix dementia care ${ }^{, 40}$ suggest that care needs to be improved.

The studies were also only undertaken in a limited number of Western countries (North America, Sweden and the UK), making it impossible to be confident of their relevance to other countries because of the diversity of healthcare contexts.

There was also a perhaps surprising lack of detail given about the older people and about the study participants. For example, participant ethnicity and religion and relationships with family carers were seldom if ever reported. The inclusion of such information would further our understanding here.

It was also striking that, apart from two studies, ${ }^{31} 35$ all studies included some participant observation. Again, this means that the majority were researchers' observations of their experiences. The lack of reported considerations of reflexivity are therefore particularly surprising.

Another noticeable feature of the included studies was how few individual researchers have published on the topic with one researcher involved in three publications. ${ }^{25-27}$ It is difficult to explain the involvement of so few researchers, but this may also reflect the challenges of undertaking research in the area and possibly also limits the breadth of the research undertaken.

\section{Future research}

Notwithstanding the ethical and practical challenges in investigating this important topic, clearly more high-quality, sensitive research into older people's experiences would help us understand and potentially improve how people die in nursing homes. Much more needs to be known about how the psychological and spiritual experiences of dying residents could be managed and how we can meet the cultural values and needs of older people in residential care facing death. Furthermore, unlike much of the research identified here, future qualitative research should be grounded in explicit, appropriate epistemological positions to enhance the transferability of the findings.

\section{CONCLUSIONS}

The findings of this review highlight numerous significant continuing issues faced by older people dying in nursing and care homes. The challenges, both practical and ethical, to investigating death may well be contributing factors to the 
limited research available on this important topic. Despite the dearth of relevant studies, this review highlighted the critical value of professional sensitivity to broader psychosocial aspects of older people's dying experience in care homes. Too often investigations have focused on aspects of care that can be more easily measured and delineated by policies and protocols. This research identifies the ongoing need for enhanced professional consciousness of psychological, social and cultural elements inherent within dying. The expereince of dying is a complex, multifaceted one, and timing of interventions, including advance care planning, can be critical to the value for dying people. In reviewing the available research, the team were struck by the many aspects of care and experiences identified that seemed potentially avoidable. The combined findings within this review suggest that much more can and should be done in understanding and supporting older people dying in nursing homes. Perhaps in the future, a more comprehensive picture might be gained by adopting an appreciative enquiry approach ${ }^{41}$ focusing on positive experiences and what works well, rather than on negative aspects of older people's experiences.

Acknowledgements Farrukh Akhtar, Jacqueline Chang, Dr Gillian Pedley, Dr Ferruccio Pelone and Dr Raymond Smith all contributed at some point to the review. The review was supported by the Faculty of Health, Social Care and Education, Kingston University and St George's, University of London. We would also like to thank the journal's peer-reviewers who made many helpful suggestions to the original version of the paper.

Contributors All authors took part in developing the review questions, designing the study, data screening and quality appraisal. NG, EM-G and AR undertook the analysis. NG led on writing the paper, and all authors contributed to and commented on the final draft.

Funding The authors have not declared a specific grant for this research from any funding agency in the public, commercial or not-for-profit sectors.

Competing interests None declared.

Patient consent Not required.

Provenance and peer review Not commissioned; externally peer reviewed.

Data sharing statement Data are not shared but may be found in the nine studies critically reviewed as part of this review. No additional unpublished data are available for this study.

Open Access This is an Open Access article distributed in accordance with the Creative Commons Attribution Non Commercial (CC BY-NC 4.0) license, which permits others to distribute, remix, adapt, build upon this work non-commercially, and license their derivative works on different terms, provided the original work is properly cited and the use is non-commercial. See: http://creativecommons.org/ licenses/by-nc/4.0/

(c) Article author(s) (or their employer(s) unless otherwise stated in the text of the article) 2018. All rights reserved. No commercial use is permitted unless otherwise expressly granted.

\section{REFERENCES}

1. Gasior K, Huber M, Lamura G, et al. In: Rodrigues R, Huber M, Lamura G, eds. Facts and figures on healthy ageing and longterm care. Vienna: European Centre for Social Welfare Policy and Research, 2012.

2. Broad JB, Gott M, Kim H, Hongsoo K, et al. Where do people die? An international comparison of the percentage of deaths occurring in hospital and residential aged care settings in 45 populations, using published and available statistics. Int $J$ Public Health 2013;58:257-67.

3. Office for National Statistics (ONS). Deaths: place of occurrence and sex by underlying cause and age group, 2004 to 2009. https:// www.ons.gov.uk/peoplepopulationandcommunity/birthsdeaths andmarriages/deaths/adhocs/005994deathsplaceofoccurrenceand sexbyunderlyingcauseandagegroup2004to2009 (accessed: 15 Dec 2017).

4. Office for National Statistics (ONS). Deaths registered in England and Wales (series DR). https://www.ons.gov.uk/peoplepopulationandc ommunity/birthsdeathsandmarriages/deaths/datasets/deathsregist eredinenglandandwalesseriesdrreferencetables (accessed: 15 Dec 2017).

5. Hansford P, Meehan H. Gold standards framework: Improving community care, end of life care. 2007;1:56-61 https://www.gold standardsframework.org.uk/cd-content/uploads/files/Library\% 2C\%20Tools\%20\%26\%20resources/Gold\%20Standards\% 20Framework\%20-\%20improving\%20community\%20care.pdf.

6. Department of Health and Social Care. End of Life Care Strategy: promoting high quality care for adults at the end of their life. 2008 https://www.gov.uk/government/publications/end-of-life-carestrategy-promoting-high-quality-care-for-adults-at-the-end-of-theirlife (accessed: 15 Dec 2017).

7. National End of Life Care Partnership. Ambitions for Palliative and End of life care a national framework for local action 2015-20. http://endoflifecareambitions.org.uk/wp-content/uploads/2015/09/ Ambitions-for-Palliative-and-End-of-Life-Care.pdf (accessed: 1 Dec 2017).

8. Smeding R, BolgerM EJ. International development of the Liverpool care pathway for the dying patient (LCP). In: Ellershaw J, Wilkinson $\mathrm{S}$, eds. Care of the dying - a pathway to excellence. 2 edn. New York: Oxford University Press, 2011.

9. Hall S, Kolliakou A, Petkova H, et al. Interventions for improving palliative care for older people living in nursing care homes. Cochrane Database Syst Rev 2011;16:CD007132. 10.1002/14651858.CD007132.

10. Kinley J, Hockley J, Stone L, et al. The provision of care for residents dying in U.K. nursing care homes. Age Ageing 2014;43:375-9.

11. Weathers $\mathrm{E}, \mathrm{O}^{\prime} \mathrm{Caoimh} \mathrm{R}$, Cornally $\mathrm{N}$, et al. Advance care planning: A systematic review of randomised controlled trials conducted with older adults. Maturitas 2016;91:101-9.

12. Brinkman-Stoppelenburg A, Rietjens JA, van der Heide A. The effects of advance care planning on end-of-life care: a systematic review. Palliat Med 2014;28:1000-25.

13. Addicott R. Supporting care home residents at the end of life. Int $J$ Palliat Nurs 2011;17:183-7.

14. Mathie E, Goodman C, Crang C, et al. An uncertain future: the unchanging views of care home residents about living and dying. Palliat Med 2012;26:734-43.

15. Towsley G, Hirschman KB, Ersek M. Mixed messages: Nursing home resident preferences about care at end of life (761). J Pain Symptom Manage 2011;41:310.

16. Fosse A, Schaufel MA, Ruths S, et al. End-of-life expectations and experiences among nursing home patients and their relatives--a synthesis of qualitative studies. Patient Educ Couns 2014;97:3-9.

17. Fleming J, Farquhar M, Brayne $\mathrm{C}$, et al. Death and the Oldest Old: Attitudes and Preferences for End-of-Life Care--Qualitative Research within a Population-Based Cohort Study. PLoS One 2016;11:e0150686

18. Hanson LC, Eckert JK, Dobbs D, et al. Symptom experience of dying long-term care residents. J Am Geriatr Soc 2008;56:91-8.

19. Centre for Reviews Dissemination (CRD). Systematic reviews: Crd's guidance for undertaking reviews in health care. York: University of York, 2009.

20. Moher D, Liberati A, Tetzlaff J, et al. the PRISMA statement. Ann Intern Med 2009;151:264-9.

21. Menzies-Gow E, Greenwood N, Nilsson D, et al. The experience of dying in care home: the perspectives of older people, their families and healthcare professionals. A systematic review. http://www.crd. york.ac.uk/PROSPERO/display_record.php?ID=CRD42017055954.

22. Greenwood N, Mackenzie A, Cloud GC, et al. Informal primary carers of stroke survivors living at home-challenges, satisfactions and coping: a systematic review of qualitative studies. Disabil Rehabil 2009;31:337-51.

23. Mays $\mathrm{N}$, Pope $\mathrm{C}$. Assessing quality in qualitative research. $B M J$ 2000;320:50-2.

24. Popay J, Rogers A, Williams G. Rationale and standards for the systematic review of qualitative literature in health services research. Qual Health Res 1998;8:341-51.

25. Kayser-Jones J. The experience of dying: an ethnographic nursing home study. Gerontologist 2002;42:11-19.

26. Kayser-Jones J, Schell E, Lyons W, et al. Factors that influence endof-life care in nursing homes: the physical environment, inadequate staffing, and lack of supervision. Gerontologist 2003;43:76-84. 
27. Chan J, Kayser-Jones J. The experience of dying for Chinese nursing home residents: cultural considerations. J Gerontol Nurs 2005;31:26-32

28. Bern-Klug M, Gessert CE, Crenner CW, et al. "Getting everyone on the same page": nursing home physicians' perspectives on end-oflife care. J Palliat Med 2004;7:533-44.

29. Österlind J, Ternestedt B-M, Hansebo G, et al. Feeling lonely in an unfamiliar place: older people 's experiences of life close to death in a nursing home. Int $\mathrm{J}$ Older People Nurs 2017:12:e12129:1-8.

30. Forbes $\mathrm{S}$. This is Heaven's waiting room: end of life in one nursing home. J Gerontol Nurs 2001;27:37-45.

31. Dwyer LL, Hansebo G, Andershed B, et al. Nursing home residents' views on dying and death: nursing home employee's perspective. Int J Older People Nurs 2011;6:251-60.

32. Whitaker A. The body as existential midpoint - the aging and dying body of nursing home residents. J Aging Stud 2010;24:96-104

33. Goodridge D, Bond JB, Cameron C, et al. End-of-life care in a nursing home: a study of family, nurse and healthcare aide perspectives. Int J Palliat Nurs 2005;11:226-32.

34. Vohra JU, Brazil K, Szala-Meneok K. The last word: family members' descriptions of end-of-life care in long-term care facilities. J Palliat Care 2006;22:33-9.
35. Brayne S, Lovelace H, Fenwick P. End-of-life experiences and the dying process in a gloucestershire nursing home as reported by nurses and care assistants. American Journal of Hospice and Palliative Medicine® 2008;25:195-206.

36. Cagle JG, Unroe KT, Bunting M, et al. Caring for dying patients in the nursing home: Voices from frontline nursing home staff. J Pain Symptom Manage 2017;53:198-207.

37. Andersson S, Lindqvist O, Fürst CJ, et al. End-of-life care in residential care homes: a retrospective study of the perspectives of family members using the VOICES questionnaire. Scand J Caring Sci 2017:31:72-84.

38. Lin R. Case study research. Design and methods: Applied social research methods series 5. 2nd edn. Thousand Oaks: Sage, 2003.

39. Abraham S, Menec V. Transitions between care settings at the end of life among older homecare recipients: A population-based study. Gerontol Geriatr Med 2016;2.

40. Alzheimer's Society. Fix dementia care: NHS and care homes report. 2016 https://www.alzheimers.org.uk/downloads/file/3026/fix dementia care nhs and care homes report (accessed 15 Dec 2017).

41. Cooperrider D, Whitney D, Stavros JM. Appreciative Inquiry Handbook: For Leaders of Change. 2nd ed. Brunswick: OH Crown Custom Publishing, 2008. 
Correction: Experiences of older people dying in nursing homes: a narrative systematic review of qualitative studies

Greenwood N, Menzies-Gow E, Nilsson D, et al. Experiences of older people dying in nursing homes: a narrative systematic review of qualitative studies. BMJ Open 2018; 8(6):e021285. doi: 10.1136/bmjopen-2017-021285.

There is an error in the references. Reference number 17 is cited as:

Fleming J, Farquhar M, Brayne C, et al. Death and the oldest old: attitudes and preferences for end-of-life care-Qualitative research within a population-based cohort study. PLoS One 2016;11:e0150686. doi:10.1371/journal.pone.0150686

However, the correct reference is:

Fleming J, Calloway R, Perrels A, et al. Dying comfortably in very old age with or without dementia in different care settings - a representative "older old" population study. BMC Geriatr 201717:222. doi:10.1186/s12877-017-0605-2

Open access This is an open access article distributed in accordance with the Creative Commons Attribution Non Commercial (CC BY-NC 4.0) license, which permits others to distribute, remix, adapt, build upon this work non-commercially, and license their derivative works on different terms, provided the original work is properly cited and the use is non-commercial. See: http://creativecommons.org/licenses/by-nc/4.0/

C Article author(s) (or their employer(s) unless otherwise stated in the text of the article) 2018. All rights reserved. No commercial use is permitted unless otherwise expressly granted.

BMJ Open 2018;8:e021285corr1. doi:10.1136/bmjopen-2017-021285corr1

Check for updates 